\section{Gateways to scientific journals covering headache and pain research}

Headache and chronic pain are often ignored, misunderstood or stigmatized. Confronting their personal and social burden due to headache and chronic pain renders patients, and sometimes doctors, unable to witnesses the discomfort from headache "only" and not from cancer or heart attack, nor from other apparently more severe and disabling diseases. The real and honest confrontation of new parameters such as the time lived with disability coupled with ancient, pragmatic parameters centred on premature mortality helped the international research community realize that headache disorders stand out from other "major diseases" as both scientifically and socially important. Once this concept gained the deepmind levels of researchers and doctors, we observed the flourishing of scientific journals devoted to headache and a new boosting of interests of a broad list of journals, yet presenting hectic or null interest in headache.

Thus, a major difficulty for doctors in conducting an independent scientific education in this argument is to have access to journals presenting a wider perspective towards this argument. It has to range from genetic and biomolecular research to social aspects, from clinical reports to economic evaluation, and from critical evaluation of new and old comorbidities to innovative drug therapies.

Our readership is currently engaged in a daily battle for improving its own cognition based on an immense ground of scientific information. We can learn from clinical research reports how to increase our clinical ability to identify a new headache nano-entity or the ultimate way to enlightening one or more dark corners of headache mechanics. One major problem is that not all of us have the time to immediately compare the previous literature on which the paper was based. The authors' interpretations of the other data could be not implicit as in our experience.

The majority of doctors are discouraged and demoralized by the absence of a contemporary possibility to obtain the full text of the cited papers. We have to provide - into an online "free" full text a reference section linked to the full text of the cited article, even if they come from a different Web source or publishing network.

I suggest the use of the following gateways to gain the more common scientific journals reporting papers on headache fields. Articles may be downloaded on a pay-per-view basis.

\section{SPRINGERLINK}

http://www.springerlink.com

- The Journal of Headache and Pain http://www.springerlink.com/journals/jheadpain

- Journal of Neurology http://www.springerlink.com/journals/00415

- Neurological Sciences http://www.springerlink.com/journals/neurolsci

\section{BLACKWELL SYNERGY}

http://www.blackwell-synergy.com

Cephalalgia http://www.blackwellpublishing.com/journals/cha - Headache: The Journal of Head and Face Pain http://www.blackwellpublishing.com/journals/hed

- Acta Neurologica Scandinavica http://www.blackwellpublishing.com/journals/ane

- European Journal of Neurology http://www.blackwellpublishing.com/journals/ene

\section{LWWONLINE}

http://lwwonline.com/

- Neurology http://www.neurology.org

- Current Opinion in Neurology http://www.coneurology.com

Neurology Today http://www.neurotodayonline.com

- Neuroreport http://www.neuroreport.com

- The Neurologist http://www.theneurologist.org

The Clinical Journal of Pain http://www.clinicalpain.com

\section{SCIENCEDIRECT}

http://www.sciencedirect.com

- Pain http://www.sciencedirect.com/science/journa/03043959

- European Journal of Pain http://www.sciencedirect.com/science/journa/10903801

- Acute Pain http://www.sciencedirect.com/science/jour$\underline{\text { na/13660071 }}$

\section{CURRENT REPORTS}

http://www.current-reports.com

Current Pain and Headache Reports http://www.currentreports.com/home journal.cfm?journalID=PA

As all of us complete this virtual scientific trip into the chosen paper, we reach the most complete coverage of why and how the scientific information has been built and then we can add our personal ranking to the internationally known ones (IF, SCI, etc.). Thus, you can select these Web addresses and add them to the "bookmarks" of your desktop.

The ultimate problem regarding how we can absorb the scientific information coming from a peer-reviewed journal is complex, and progress for a final resolution could be slower than most of us would like. We might wonder if the obvious solution - to move to these Web facilities - should not be reached. 